\title{
Down to earth
}

\section{Why soil — and soil science — matters.}

\section{Dan H. Yaalon}

$\mathrm{M}$ any ancient religions recognized the importance of soils, and their customs evolved into a spiritual attachment to the life-giving Earth. But surprisingly, ancient and classical scholars did not study the nature of soil. Early scientists also ignored it. For instance, the famous naturalist Alexander von Humboldt (1769-1859), a founder of plant geography, never compared the soils of the several continents on which he studied the distribution of plant species. This attitude still crops up frequently. The Fontana History of the Environmental Sciences (1992) contains no mention of soils as a branch of environmental science, although other Earth sciences are included. Is soil just dirt, too commonplace for mention or study?

I am a pedologist - an Earth scientist focusing on the origin and distribution of soils in relation to the history of landscapes. We have much to learn about non-arable soils, and must try to integrate our knowledge into a holistic view of the Earth's dynamics and biogeochemical transformations. Soils are economically and socially important. They can even have beauty: the soil scientist Hans Jenny (1899-1992) was enchanted by the soils depicted in paintings. To paraphrase Leonardo da Vinci: why do we know more about distant celestial objects than we do about the ground beneath our feet?

New ideas about the nature and origin of soils emerged only in the second half of the nineteenth century. V. V. Dokuchaev (18461903) and E. W. Hilgard (1833-1916), both mineralogists and chemists by training, recognized in their soil surveys that climate, vegetation and substrate were all important, and saw the importance of soil horizonation - the development of different layers of soil parallel to the surface - in representing and elucidating a landscape's history. Dokuchaev had imperial backing in Russia, and several distinguished followers; Hilgard, although a respected university professor in the United States, was not favoured by the establishment. An opportunity to promote his ideas was lost when J. W. Powell and he failed to establish a geological-agricultural (soil) survey in the US Geological Survey. Language barriers hindered communication between soil scientists, and the spread of knowledge was painfully slow, even after the new Russian pedogenetic ideas were presented at world exhibitions and translated.

Gradually, topographical and biological

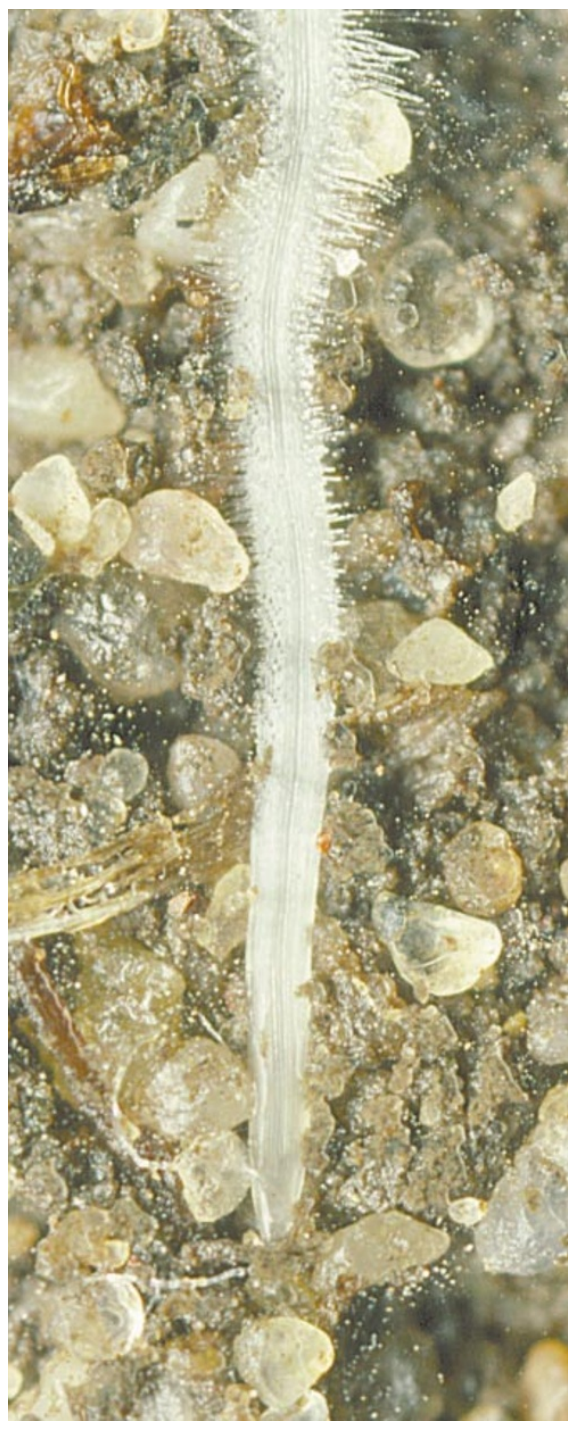

Root of life: the soil forms the central link

between the climate and biogeochemical systems.

effects, and the duration of soil-formation processes were all recognized as equally important factors in soil evolution. It took more than one generation before C. F. Marbut (1863-1935) included the concepts of external and internal environmental effects on pedogenesis in the influential US Department of Agriculture soil survey, established by Milton Whitney in 1899 . When Jenny submitted his now-classic book on the 'five soil-forming factors' and the quantitative approach to single-factor soil-forming functions, it was at first rejected for publication. It took five years before the book was eventually published in 1941.

The importance of soils as a life-support system and in the production of food and fibre was duly recognized. There were spec- o paraphrase
Leonardo da Vinci: why do we know more about distant celestial objects than we do about the ground beneath our
feet?

tacular achievements, helping to feed the ever-growing population. Nowadays, most of the 50,000 soil scientists work in agronomic institutes, studying the composition and dynamics of soils in ever greater detail. Yet less than $5 \%$ of the global agricultural research budget goes on soil research.

The use of soils in road building, construction, ceramics and the cement and aluminium industries is another area where a basic knowledge of soil and landscapes is important. Technological institutes promote this study, which is anchored in ancient practical applications.

Soils teem with life. The Nobel laureate Selman Waksman (1888-1973) isolated streptomycin from soil biota, and the preservation of pedodiversity and biodiversity may aid similar research in the future. Also, it seems plausible that biological evolution was influenced and constrained by the properties of the soil environment, an attractive field of unexplored research. For Earth scientists, ancient and buried soils are one of the better proxies for reconstructing past climate and the development of the landscape.

But it is as the transformer, regulator, buffer and filter of water, nutrients and other dissolved and dispersed compounds that soils are most important to humankind - a focal and connecting link between the biogeochemical cycles of the Earth and the dynamic atmospheric system. In the conceptual wiring diagram of the International Geosphere-Biosphere Program the soil system, especially its carbon dynamics, is the central link between the physical climate and biogeochemical systems. It is therefore a major route to understanding and predicting the effects of human actions on the Earth.

Dan H. Yaalon is at the Institute of Earth Sciences, Hebrew University, Givat Ram Campus,

Jerusalem 91904, Israel. 